\title{
The taxonomy of the endemic golden palm civet of Sri Lanka
}

\author{
COLIN P. GROVES ${ }^{*}$, CHANNA RAJAPAKSHA ${ }^{2}$ and \\ KELUM MANEMANDRA-ARACHCHI ${ }^{2}$
}

\author{
${ }^{1}$ School of Archaeology \& Anthropology, Australian National University, Canberra, ACT 0200, \\ Australia \\ ${ }^{2}$ Wildlife Heritage Trust of Sri Lanka, 95 Cotta Road, Colombo 8, Sri Lanka
}

Received 17 September 2007; accepted for publication 15 January 2008

\begin{abstract}
Two species of palm civet are currently known from Sri Lanka: the widespread common species, Paradoxurus hermaphroditus (Pallas, 1777), and the endemic golden species, Paradoxurus zeylonensis (Pallas, 1778). The latter has two 'morphs', one golden and one dark brown, both of which are recorded from all three major biotic zones in Sri Lanka (wet zone, dry zone, and cloud forest). We have examined specimens of both 'morphs' from all zones, and conclude that there are actually several species involved: names are available for two of them, we describe a third as a new species, and we draw attention to a probable fourth species, based on two distinctive specimens, the provenance of which are unfortunately unknown. The name zeylonensis probably does not apply to a golden palm civet at all. (C) 2009 The Linnean Society of London, Zoological Journal of the Linnean Society, 2009, 155, $238-251$.
\end{abstract}

ADDITIONAL KEYWORDS: New species - Paradoxurus aureus - Paradoxurus montanus - Paradoxurus stenocephalus - Paradoxurus zeylonesis.

\section{INTRODUCTION}

Two species of palm civet (Paradoxurus) are deemed to occur in Sri Lanka. One, the common palm civet or toddy cat, Paradoxurus hermaphroditus (Pallas, 1777), belongs to a species that is widespread in South Asia and, as presently recognized, in South East Asia; the other, generally known as the golden palm civet, Paradoxurus zeylonensis (Pallas, 1778), is indigenous to Sri Lanka, but a closely related species, the brown palm civet, Paradoxurus jerdoni Blanford, 1885, lives in southern India. Both Sri Lankan species are commonly known as kalawedda in Sinhala and maram nai in Tamil. The name uguduwa is also applied to the common species in Sinhala, and the golden palm civet is called Pani uguduwa (literally, honey-coloured palm civet) or Sapumal kalawaddha [sapu is the name of two trees, champak (Michelia) and ylang-ylang (Cananga); hence, sapu flower-smelling palm civet], and sometimes Ranhothambuwa. Externally, the two Sri Lankan

*Corresponding author. E-mail: colin.groves@anu.edu.au species are readily distinguished by the mottled or brindled pelage, dark tail, and (typically) the black and white facial mask, and black facial vibrissae, of the common species, versus the uniform pelage and pale vibrissae of the golden species, which also has a reversed hair stream on the nape (in which it resembles the brown palm civet), and a somewhat shorter, usually paler tail; cranially, they are much alike, but the golden palm civet has a rather narrower skull with smaller cheekteeth (carnassials). Phillips (1984: 300-306) gives details of these two putative species.

Despite its name, the golden palm civet is not necessarily golden in colour: there are both golden and dark-brown morphs. The pelage of the golden morph is genuinely golden, from a beautiful bright red-gold to a more faded and brownish golden tone, whereas individuals of the brown morph vary from dark greyish brown to nearly black. But, during field studies over the past several years, one of us (CR) formed the very definite impression that the golden and the brown 'morphs' are actually different species, and collected and purchased skulls and skins from 
village repositories to try and test this. In this paper we test the hypothesis that $P$. zeylonensis, as currently constituted, might consist of more than one species.

\section{MATERIAL AND METHODS}

The material studied is listed below.

Skins: Natural History Museum, London (BMNH), 12; National Museum of Sri Lanka, Colombo (NMC), 12; Colombo University collection (CU), seven.

Skulls: BMNH, eight (plus one with a damaged mandible only); CU, 12.

The BMNH and NMC material was studied by CPG, who also examined and measured three specimens from the $\mathrm{CU}$ collection in order to ensure the consistency of our technique. The other skulls from the CU collection were measured by KM-A.

$\mathrm{CR}$ also observed numerous living individuals in the field, and live-trapped 14 for closer examination and study; a series of reports is being prepared. Camera-trapping has hitherto not been possible, but its feasibility is now being investigated for the future.

The measurements taken on the skulls were as follows: bican, greatest breadth of rostrum in canine region; bizyg, greatest breadth across the zygomatic arches; bullbr, greatest breadth of auditory bulla; cbl, condylobasal length (this measurement was often impossible to take because of damage to the foramen magnum region); gtl, greatest skull length, from anterior point of premaxillae to posterior point of occipital crest; ht, skull height, measured vertically from basilar suture (spheno-occipital synchondrosis) to highest point on cranial vault (exclusive of sagittal crest); interb, width between auditory bullae; interpteryg, greatest width of interpterygoid fossa; jawl, greatest horizontal length of mandibular corpus, measured parallel with tooth row; occcrest, greatest breadth of occipital crest; p4l, length of $\mathrm{P}^{4}$ (upper carnassial); pall, greatest length of palate, measured from anterior point of premaxillae to posterior edge of palate; ramusht, greatest vertical height of ascending ramus, measured from inferior margin of mandibular corpus to top of coronoid process.

Many (not all) of the skins had recorded associated flesh measurements: head + body, tail, hindfoot, ear, and sometimes weight. These measurements, taken by diverse individuals probably by diverse methods, must be used cautiously, but nevertheless give a general idea of external size and proportions.

Measurements were analysed first by principal components analysis and subsequently by discriminant analysis, using SPSS v14.0, and were compared individually using box plots and bivariate scatter plots with SPSS v14.0.
We have found no differences between males and females in either skull or pelage, and so we have combined them in our analysis. All skulls used for this study are adult, with the basilar suture fused; although many of the skins are not paired with skulls, all appear to be fully grown or nearly so. Very young juveniles have a darker, more fluffy, pelage than older juveniles or adults, and we have not considered them in this study.

\section{RESULTS \\ Pelage}

The skins (Fig. 1) clearly assort into six categories, of which the first three are 'brown morph', and the remaining three are 'golden morph'.

1. Dark, slightly greyish-toned wood-brown, with a yellowish-white tail tip. Eight skins fall into this category: four from Mousakande, Gammaduwa, Knuckles Range $\left(7^{\circ} 34^{\prime} \mathrm{N}, \quad 80^{\circ} 42^{\prime} \mathrm{E}, \quad 610\right.$ $910 \mathrm{~m}$ a.s.l.; three at $\mathrm{BMNH}$, one at $\mathrm{NMC}$ ), and one each from Maha Oya $\left(7^{\circ} 31^{\prime} \mathrm{N}, 81^{\circ} 20^{\prime} \mathrm{E}\right.$, $100 \mathrm{~m}$ a.s.l.; $\mathrm{BMNH})$, Viharahalvillewa $\left(8^{\circ} 40^{\prime} \mathrm{N}\right.$, $80^{\circ} 40^{\prime} \mathrm{E}, 130 \mathrm{~m}$ a.s.l.; NMC), Moneragala $\left(6^{\circ} 52^{\prime} \mathrm{N}\right.$, $81^{\circ} 20^{\prime} \mathrm{E}, \quad 160 \mathrm{~m}$ a.s.l.; CU), and Kurunegala $\left(7^{\circ} 29^{\prime} \mathrm{N}, 80^{\circ} 21^{\prime} \mathrm{E}, 300 \mathrm{~m}\right.$ a.s.l.; CU). Gammaduwa is in submontane habitat, and the other four localities are in the dry zone. CR has live-trapped several palm civets of this type in the Knuckles Range, at Memure and Elukumbura; one of them is illustrated here (Fig. 1C).

2. A darker version of (1). This is represented by a single, juvenile skin, the type of Paradoxurus montanus Kelaart, 1852 , from Newara Eliya $\left(6^{\circ} 58^{\prime} \mathrm{N}\right.$, $80^{\circ} 46^{\prime} \mathrm{E}, 2000 \mathrm{~m}$ a.s.l.; BMNH), in the cloud forest of the Central Highlands. In this specimen, the tail tip is lost, but some of a terminal yellow zone remains. Save for its thicker fur, there is very little difference between this skin and group 1 .

3. Lighter brown, with a thin but distinct darker brown dorsal stripe from the withers to the tail root, flanked on each side by a shorter stripe that begins on the lumbars, with a short white tail-tip. There are only two skins of this type, and they are in series: BMNH 77.11.1.3 and BMNH 77.11.1.4, ticketed only with 'Ceylon, confined to the Hills. Whyte'. We discovered a death notice in the Otago Daily Times (New Zealand) published on 22 March 1875: 'On the 18th December 1874 at Inver Cottage, Strathray, Perthshire, Barbara Campbell Gibson, wife of John Whyte, late of Norwood Estate, Ceylon'. Norwood Estate is in the Dickoya region at the eastern end of the Bogawantalawa valley, at about $1500 \mathrm{~m}$ a.s.l. If we have correctly identified the collector of these two specimens, and 

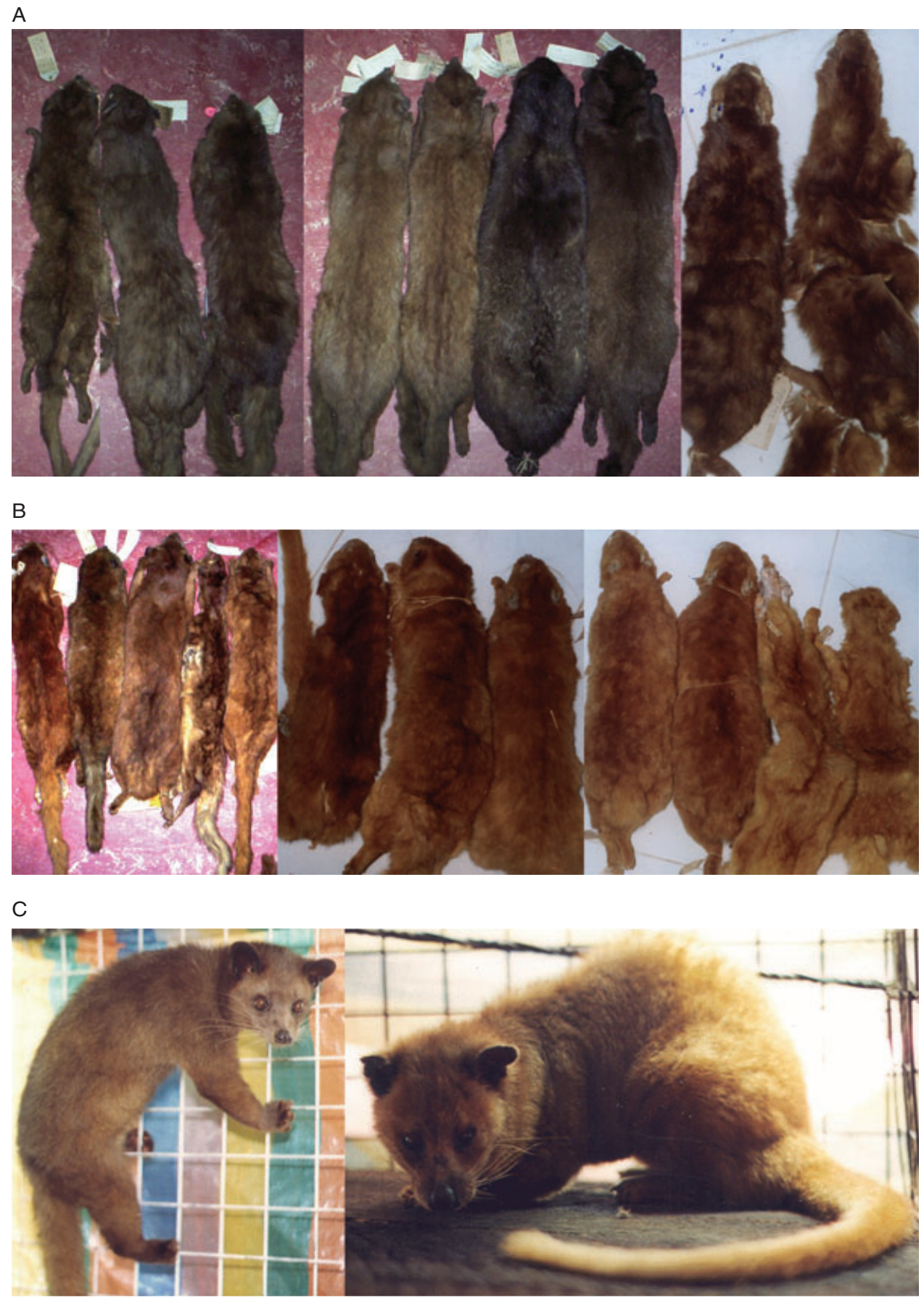

Figure 1. A, dark skins. First panel, from left to right: BM(NH) 27.11.28.1, Mousakande, Gammaduwa, Knuckles Range, 914 m a.s.l. (submontane); BM(NH) 33.2.1.1, Maha Oya, E.P. (dry zone); BM(NH) 52.5.9.17, Newara Eliya, type of Paradoxurus montanus (cloud forest). Second panel: $\mathrm{BM}(\mathrm{NH})$ 77.11.1.4 and 77.11.1.3, 'Ceylon, confined to the hills' (presented by Whyte); plus two Paradoxurus jerdoni. Third panel: NMC 41H, Mousakande, Gammaduwa, Knuckles Range, 610 m a.s.l. (submontane); NMC 42M, Moneragala, $6552^{\prime} \mathrm{N}, 81^{\circ} 20^{\prime} \mathrm{E}$ (dry zone). B, gold skins. First panel: BM(NH) 50.19, Peradeniya (submontane wet zone); BM(NH) 52.5.9.18, Newara Eliya (cloud forest); BM(NH) 49.579, Galapitakunde Estate, 1066 m a.s.l., Namunukula, Uva Prov. (cloud forest); BM(NH) 33.7.24.1, Koslanda, Lipton's Tea Estate (dry zone); BM(NH) 50.1494, Panama, Sea Coast, E.P. (dry zone). Second panel: NMC 42, Timbulketiya, $6^{\circ} 24^{\prime} \mathrm{N}, 8^{\circ} 47^{\prime} \mathrm{E}$ (borders of wet and dry zones in south); NMC 42A, Colombo (wet zone); NMC 42B, Wattakeliya, $7^{\circ} 34^{\prime} \mathrm{N}, 7^{\circ} 46^{\prime} \mathrm{E}$ (borders of wet and dry zones on west coast). Third panel: NMC 42C, 42D, 42F, 42G, all from Gammaduwa, Knuckles Range (42F is from Mousakande, $975 \mathrm{~m}$ a.s.l.). C, dark (left) and golden (right) animals, both from the Knuckles Range. 
the general area in which they were collected, then these skins are likely to have come from the western part of the Central Highlands, in the vicinity of the Peak Wilderness, perhaps in cloud forest.

4. Red-gold, with little variation in tone or markings. Eight skins fall into this category: four from Gammaduwa (NMC), one each from Colombo, Timbulketiya $\left(6^{\circ} 24^{\prime} \mathrm{N}, 80^{\circ} 47^{\prime} \mathrm{E}\right)$, Wattakeliya $\left(7^{\circ} 34^{\prime} \mathrm{N}\right.$, $79^{\circ} 46^{\prime} \mathrm{E}$ ) (all these three in NMC), and Peradeniya $\left(7^{\circ} 15^{\prime} \mathrm{N}, 80^{\circ} 36^{\prime} \mathrm{E}\right.$; BMNH). CR live-trapped a specimen of this type at Kalupahana in the Knuckles Range (Fig. 1C), but it is not abundant there. Gammaduwa and Peradeniya are submontane, Colombo is in the wet zone, and the other two localities are on the borders between wet and dry zones, Timbulketiya is in the south of Sri Lanka whereas Wattakeliya is a wetlands habitat on the West Coast.

5. Somewhat more golden brown, and less reddish. Two skins: Newara Eliya and Namunukula $\left(6^{\circ} 52^{\prime} \mathrm{N}, 81^{\circ} 07^{\prime} \mathrm{E}\right)$, both BMNH. Namunukula is a small isolated mountain area, east of the Central Highlands, incorporating a small patch of cloud forest, and the specimen was taken at 3500 feet (1070 $\mathrm{m}$ a.s.l.), evidently in the cloud forest zone.

6. Not unlike (5), but somewhat more dull in tone, and with three thin but clear dark-brown stripes down the back, from the withers to near the tail base, as in (3), but the lateral stripes beginning much further forwards. Two skins: Koslanda $\left(6^{\circ} 43^{\prime} \mathrm{N}, 81^{\circ} 01^{\prime} \mathrm{E}, 550 \mathrm{~m}\right.$ a.s.l.), Panama $\left(6^{\circ} 45^{\prime} \mathrm{N}, 81\right.$ $47^{\prime} \mathrm{E}$, sea level), both BMNH. Both of these are from the dry zone. During the course of his fieldwork, CR live-trapped a civet identical to these two skins near Walpolamulla, $625 \mathrm{~m}$ a.s.l., in the Knuckles Range at $7^{\circ} 30^{\prime} \mathrm{N}, 80^{\circ} 46^{\prime} \mathrm{E}$.

The skins thus include dark specimens from the dry, submontane and upper montane (cloud forest) zones, and golden specimens from these zones, as well as the lowland wet zone. There is little evidence for geographic variation in pelage among the dark specimens, with the exception of the two enigmatic Whyte skins; among the golden specimens, there is little difference between the wet-zone (including submontane) and cloud-forest specimens, but there is a noticeable difference between these and the two dryzone specimens.

Living examples of dark and golden animals, both from the Knuckles Range, are shown in Figure 1C.

\section{CRANIAL CHARACTERS}

The skulls group into the six categories outlined above as follows.
1. Dark dry: nine. There are also three skulls (CU), known to have been of dark specimens, from submontane habitats in the wet zone (Sinharaja, Ratnapura, and Kandy); these are provisionally kept separate for the analysis.

2. Dark cloud forest: one (the type of montanus).

3. Whyte collection: two (one incomplete).

4. Gold wet: two.

5. Gold cloud forest: two (one incomplete).

6. Gold dry: two.

All of the skulls associated with golden skins (groups 4-6) can be differentiated from all of those associated with dark skins (groups 1-3). Skulls of the golden form have a higher, more rounded braincase (this appears to be somewhat less marked in the two dry-zone skulls than in those from the wet zone and cloud forest), a wider muzzle, and a wide square occipital crest, the sides of which are parallel instead of converging backwards (Fig. 2). In the mandible, the coronoid process in skulls of the golden form is more curved backwards. At similar ages, the cheek teeth of skulls of the golden form appear to be less worn than those of the dark form.

\section{CRANIOMETRICS: MULTIVARIATE ANALYSES}

Nine measurements were available on most of the skulls, and so these were put into an exploratory principal components analysis to see if any patterns were evident.

It was clear that, metrically, the three available golden-morph skulls from the wet zone are very different from any other skulls, and the two available golden-morph skulls from the dry zone are somewhat different, but not greatly so, from skulls of the dark morph, which do not separate well into groups, with the exception of the enigmatic Whyte skull (Fig. 3).

There is therefore reasonable a priori evidence to allot the skulls into groups for discriminant analysis, but the groups are very small, and for obvious reasons the smaller the sizes of the groups, compared with the number of variables, the greater is the chance of a type-I error (false positive). The variable list was therefore whittled down to four: gtl, pall, bican, and occcrest. These were determined on the basis of the strength of their scores in the principal components analysis.

Figure 4 shows the results. In Figure 4A, only adult specimens were used. The wet-zone skulls of the golden morph are well removed from the others. Dryzone skulls of this morph, on the other hand, are at one edge of the dispersion of dry-zone dark-morph skulls. The dark-morph wet-zone skulls are at the other edge of the dispersion, and (just) fail to overlap. Both of the Whyte skulls are available for analysis 


\section{A}

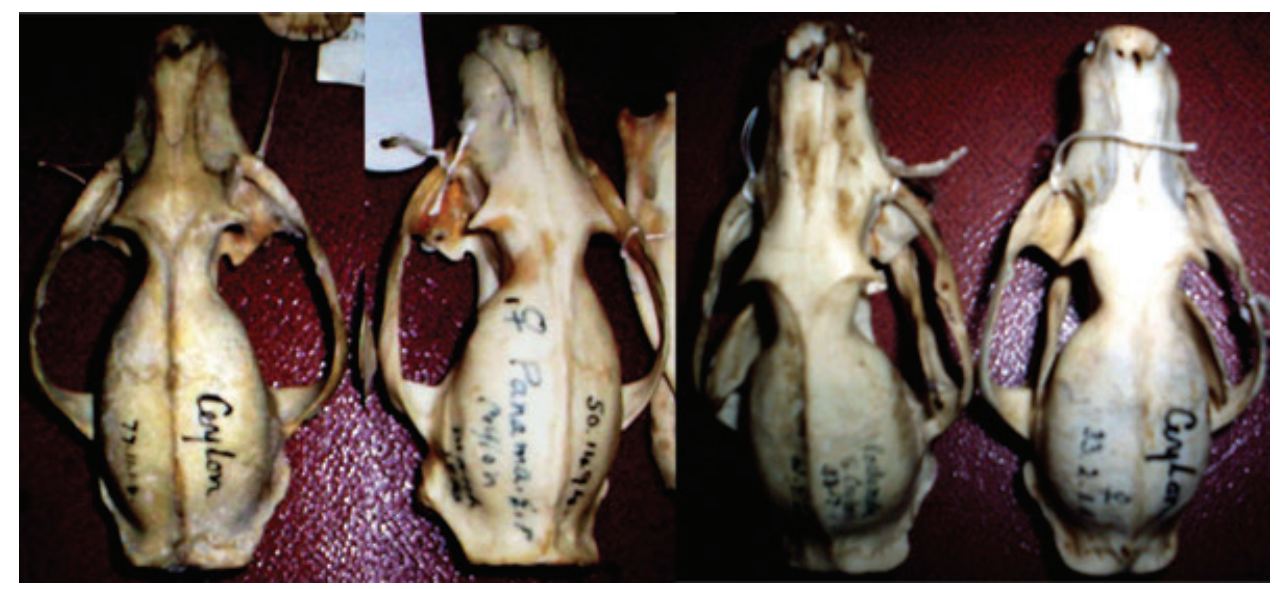

B

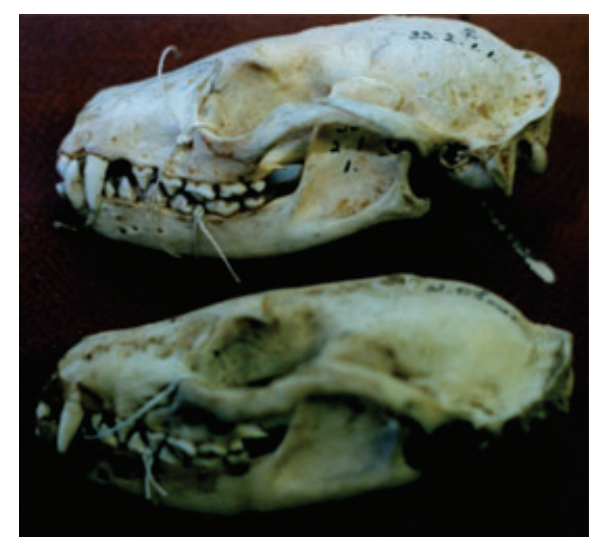

Figure 2. A, skulls from above. Left to right: $\mathrm{BM}(\mathrm{NH})$ 77.11.1.4 (Whyte); $\mathrm{BM}(\mathrm{NH})$ 50.1494, Panama (golden); $\mathrm{BM}(\mathrm{NH})$ 33.7.24.1, Koslanda (golden); BM(NH) 33.2.1.1, Maha Oya (dark). B, skulls from the side. Top: BM(NH) 33.2.1.1, Maha Oya (dark); bottom: $\mathrm{BM}(\mathrm{NH})$ 33.7.24.1, Koslanda (golden).

using this reduced variable set; one falls inside the dry-zone dark-morph dispersion, and the other falls outside.

Figure 4B depicts a new analysis incorporating a few subadult skulls, as well as (for comparative purposes) two skulls of the related species Paradoxurus jerdoni from the Western Ghats of India. The results are much the same: golden-morph wet-zone skulls are enormously different from any of the other skulls. Among dark-morph skulls this time, those from the submontane wet zone are not outside of the dispersion of those from the dry zone. The type skull of $P$. montanus, a subadult, is also within the general dark-morph dispersion, as are the two golden dryzone specimens (as in Fig. 4A). This time the two skulls from the Whyte collection are both outside of the general dark-morph dispersion, and curiously fall very close to the $P$. jerdoni specimens (note that the skins are quite different: see Fig. 1A, middle panel).
EXTERNAL MEASUREMENTS: MULTIVARIATE ANALYSIS Unfortunately, as far as external measurements are concerned, not all specimens have recorded flesh measurements, and so a different mix of groupings is available (Fig. 5). All that one can say is that golden wet-zone skins are different from dark dry-zone skins, but there is little evidence that golden cloud-forest skins differ from golden skins from the wet zone.

\section{CRANIOMETRICS: UNIVARIATE BOX PLOTS}

In terms of gtl, used here as a proxy for body size (Fig. 6), P. jerdoni is larger than any Sri Lankan form. Skulls of the golden morphs are larger than those of dark morphs, except that the Whyte skulls are also large.

In terms of bizyg (Fig. 7A), the wet-zone goldenmorph skulls and the Whyte skulls are extremely broad, whereas the dry-zone golden-morph skulls and 


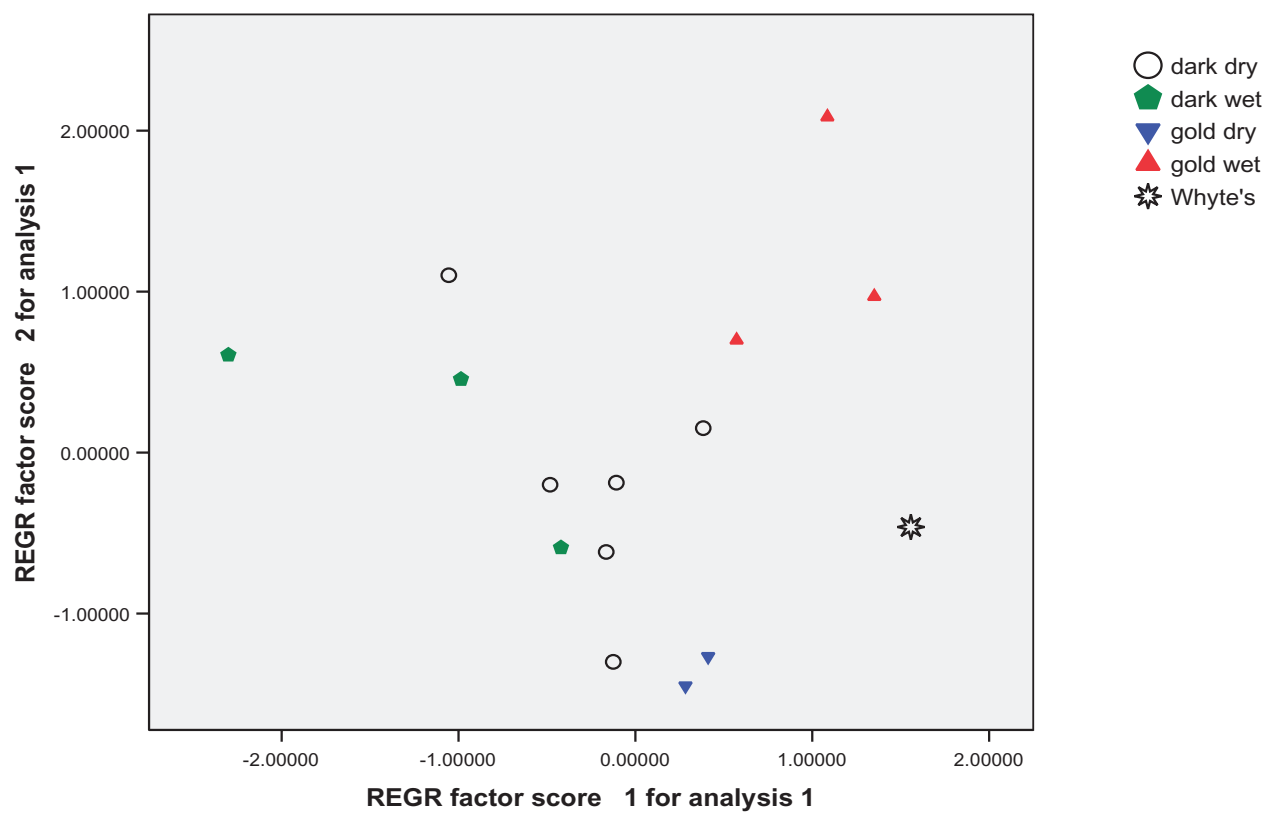

Figure 3. Principal components analysis using nine measurements (gtl, bizyg, bican, occcrest, ht, jawl, ramusht, pall, and interpteryg; see text for the abbreviations list). There are distinct differences between groups. PC1 accounts for 52.8\% of the variance, PC2 for $17.6 \%$, and PC3 (not shown) for 12.1\%. PC1 is largely a size factor, although the interpterygoid width is slightly negatively weighted. PC2 contrasts the interpterygoid, bizygomatic, and bicanine breadths (strongly positive) against greatest length, palate length, and jaw length (negative).

dark-morph skulls are narrow. The bican measurements (Fig. 7B) are different: all of the golden-morph skulls are broad-muzzled, and there is also a difference between wet-zone and dry-zone dark-morph skulls, with the former having especially narrow snouts.

Figure 8 shows box plots for the occrest measurements. Despite the differences in the shape of the crest between golden and dark forms (as described above), there is no overall difference in the breadth. Only the Whyte skulls have exceptionally narrow occipital crests.

Figure 9 presents the ht measurements. As could be predicted from the descriptions (above), the goldenmorph skulls are greater in height than the darkmorph skulls; the Whyte collection skulls are also high-crowned.

The interpteryg measurements (Fig. 10) show a difference between all wet-zone skulls and the rest, with the golden-morph dry-zone skulls having narrower fossae than the others. The great variation among dark-morph dry-zone specimens, however, suggests that these results should be viewed with caution.

\section{EXTERNAL MEASUREMENTS: UNIVARIATE AND BIVARIATE PLOTS}

Dark specimens have shorter ears than golden specimens (Fig. 11), but the incomplete sample availability so far makes this nothing more than an interesting observation.

The relative tail length is shorter in golden specimens than in dark specimens, as far as the evidence goes, except that the type of $P$. montanus ('dark cloudforest') is also short-tailed (Fig. 12).

\section{DISCUSSION}

There is clear evidence from the results for (at least?) four different taxa of 'golden palm civet': dark dry (including submontane and perhaps cloud forest), gold wet (probably including cloud forest), gold dry, and the Whyte specimens. Differences between the samples in pelage, skulls, and (where available) external measurements are entirely consistent.

Vocalisations have been rarely heard, and cannot at this time be used as supplementary taxonomic indicators. Some dark palm civets emit an attractive, perfume-like odour, but it has not been noticed from all individuals, and no chemical analysis has yet been possible. Accordingly, only 'traditional' morphological characters are available for the taxonomy of the group.

Groves (2001) presented detailed arguments in favour of the phylogenetic species concept, which is the approach that we adopt here; note that there is sympatry between at least one pair of species 


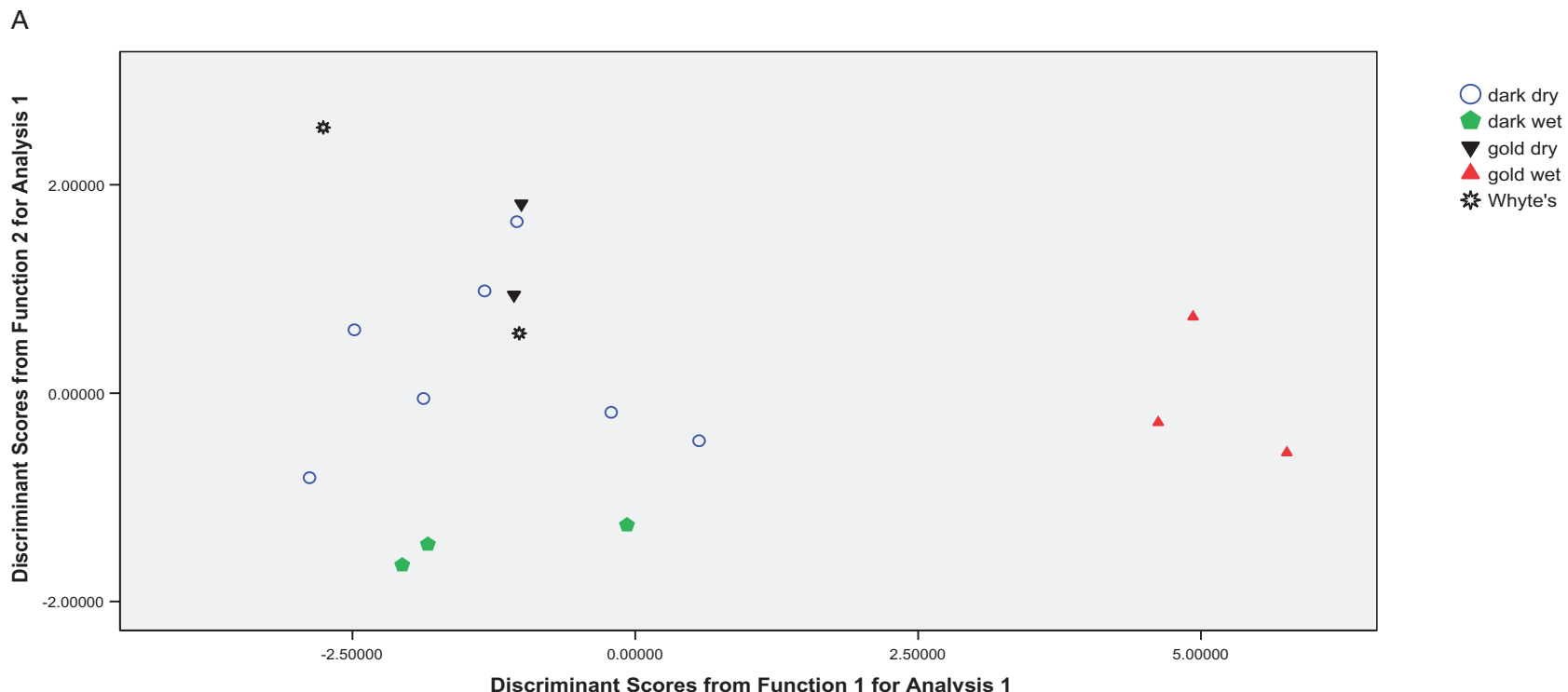

B

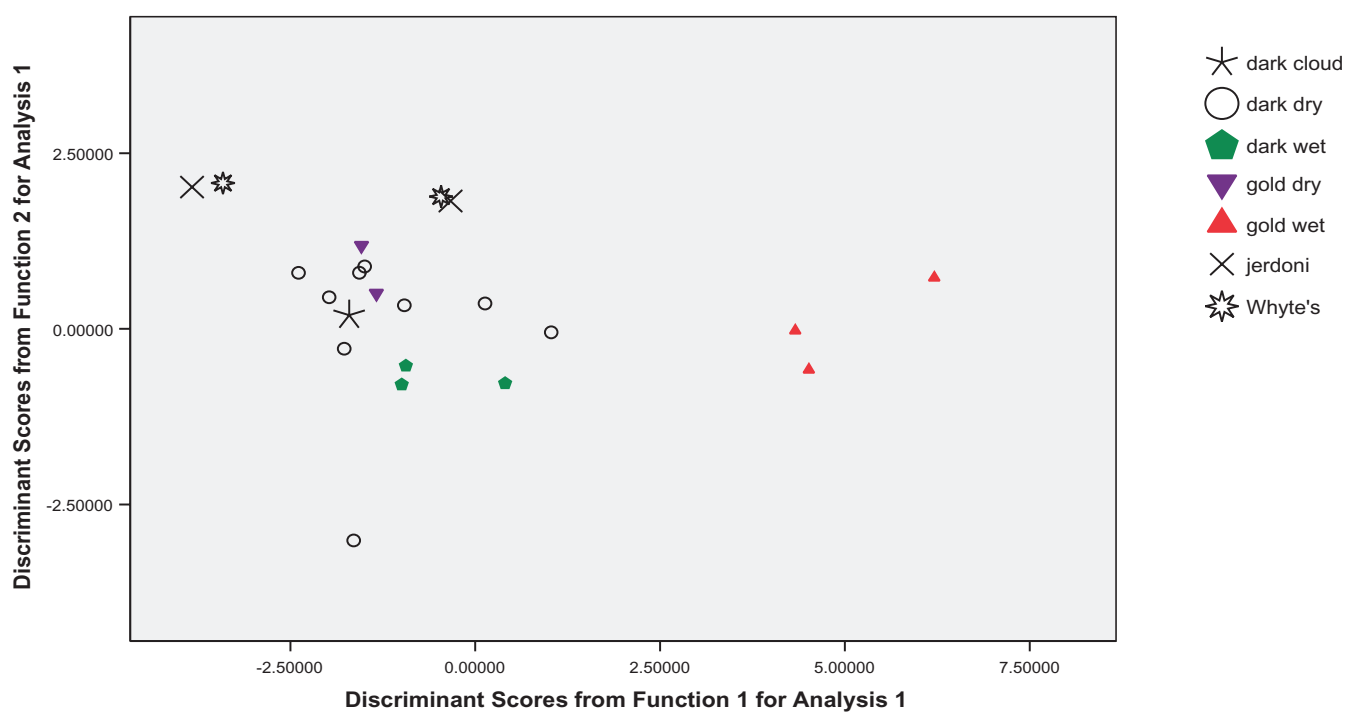

Figure 4. A, discriminant analysis, based on four variables. Adult specimens only. DF1 accounts for $95.6 \%$ of the variance, and contrasts palate length, bicanine breadth and occipital crest breadth with greatest length; DF2 accounts for $4.4 \%$, and contrasts greatest length with palate length. B, same as for (A), but including juveniles, subadults, and two skulls of Paradoxurus jerdoni. DF1 accounts for $98.2 \%$ of the variance, and, as in (A), contrasts palate length, bicanine breadth, and occipital crest breadth with greatest length; DF2 accounts for 1.8\%, and again contrasts greatest length with palate length.

(see below), so that the requirements of the biological species concept are met in this case. We maintain that there is good evidence for the existence of three different species, and that the enigmatic Whyte specimens almost certainly constitute a fourth, although, as their locality of origin is uncertain, it would be unwise to name it as a species at this time.

\section{WHAT NAMES ARE AVAILABLE FOR THESE SPECIES?}

Today, the name invariably used for what is assumed to be the one-and-only species of 'golden palm civet' is P. zeylonensis. The name Viverra zeylonensis appeared in von Schreber's 1778 Die Säugthiere, 3: 451-452, where it was attributed to Pallas, based on a specimen preserved in spirit in the Nature Cabinet of His 

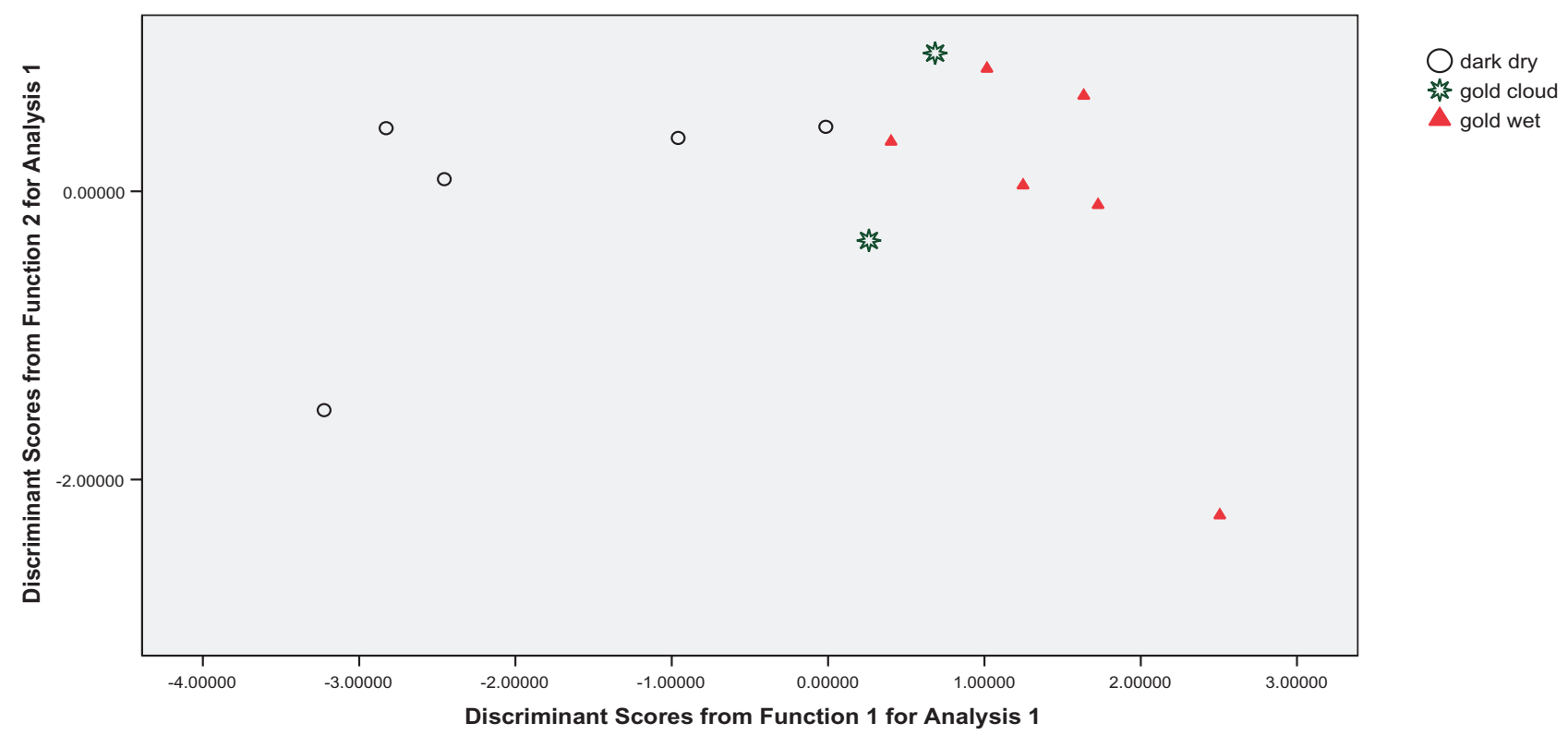

Figure 5. Discriminant analysis based on external measurements. DF1 accounts for 99.3\% of the variance, and contrasts ear and head + body with tail; DF2 accounts for only for $0.7 \%$ of the variance.

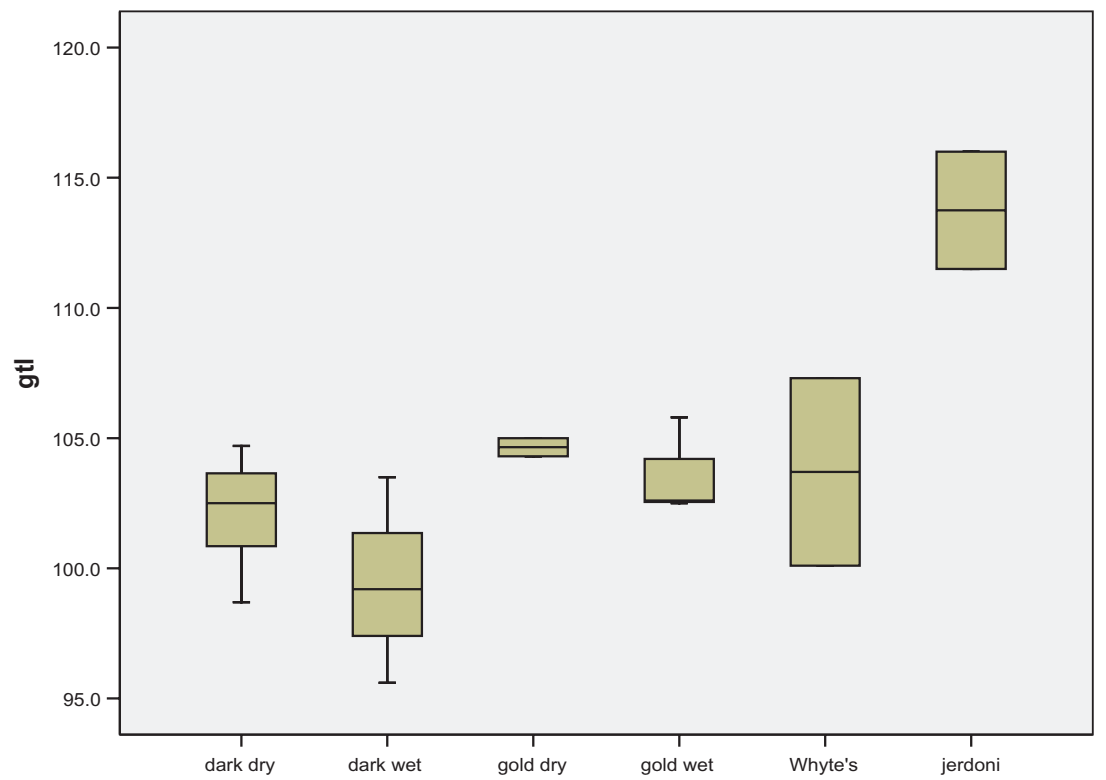

Figure 6. Size, as represented by the greatest skull length (gtl; including two representative skulls of Paradoxurus jerdoni). Sample sizes are as follows: dark dry $=7$; dark wet $=3$; gold dry $=2$; gold wet $=3$; Whyte's $=2 ;$. jerdoni $=2$.

Highness the Crown Prince... which has been seen by Professor Pallas who has given me the information which I have set down', hence the author of the name is Pallas, not von Schreber. Calling it 'Der Boshond', von Schreber wrote of its size, its teeth, tongue, and lips, its penis (a description that is sufficient to identify it as a member of the Paradoxurinae), and its five-toed feet. The part of the description that may help to identify the species is as follows.

The beard bristles stand in five rows, appear white, and reach backward to above the ears. The usual bristle-bearing warts are very clearly seen. The ears are flattened and softhaired ... The tail is almost the same length as the body, and 
A

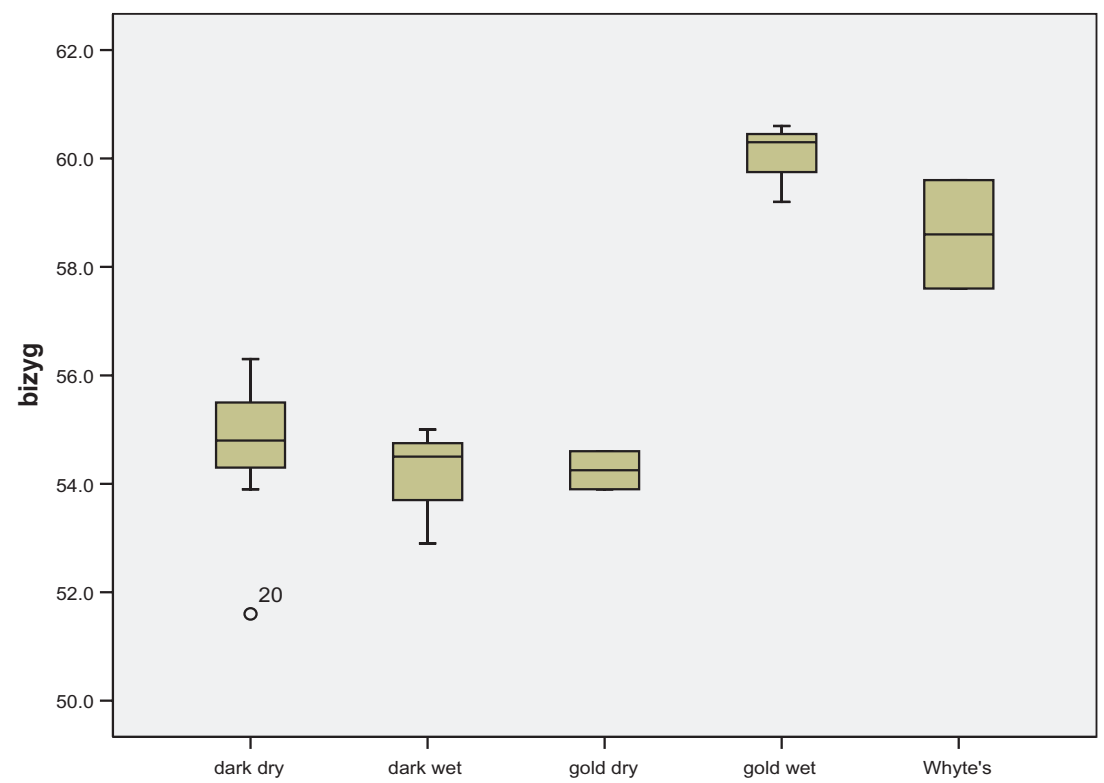

B

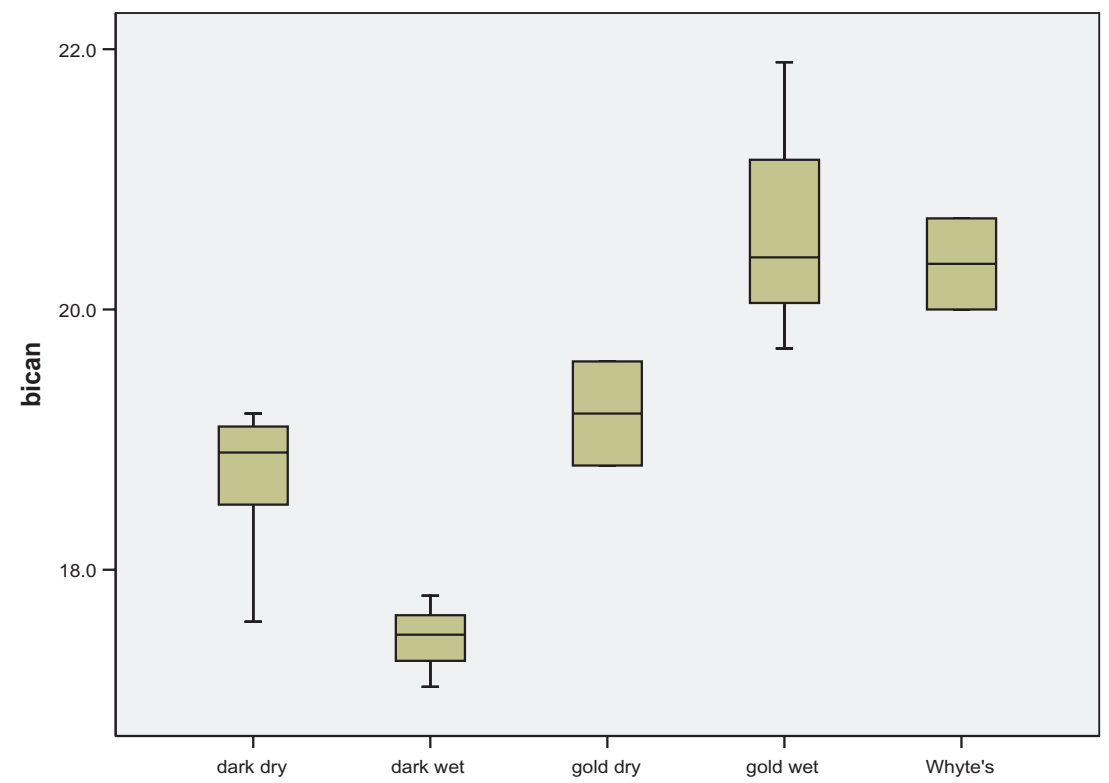

Figure 7. A, biygomatic breadth (bizyg). The sample sizes were the same as for Figure 6. B, bicanine breadth (bican). Sample sizes as for Figure 6.

is at its base somewhat thicker. The fur is marten-like, and not very thick. The colour above is grey with brown overlay, lighter below, and more blackish on the hinder part of the back and the tail. The throat is no different in colour from the neck. The native country of this animal is Ceylon ...

(von Schreber 1778; translation by CPG).

Opinions as to the specific identity of the specimen being described have fluctuated. Kelaart (1852), using the variant name zeylanicus, and referring it to Paradoxurus, accepted it as applying to a golden palm civet (although of course, if it is one, it is one of the dark forms!). Blanford (1885a) at first accepted it as referring to a golden palm civet, but five months later changed his mind (Blanford, 1885b: 782-783), later maintaining that the description of the colour was inconsistent, and doubting the correctness of the locality ('a hundred years ago localities were by no means trustworthy', drawing attention to the fact that the type specimen of Viverra hermaphrodita, likewise described by von Schreber, was said to be 


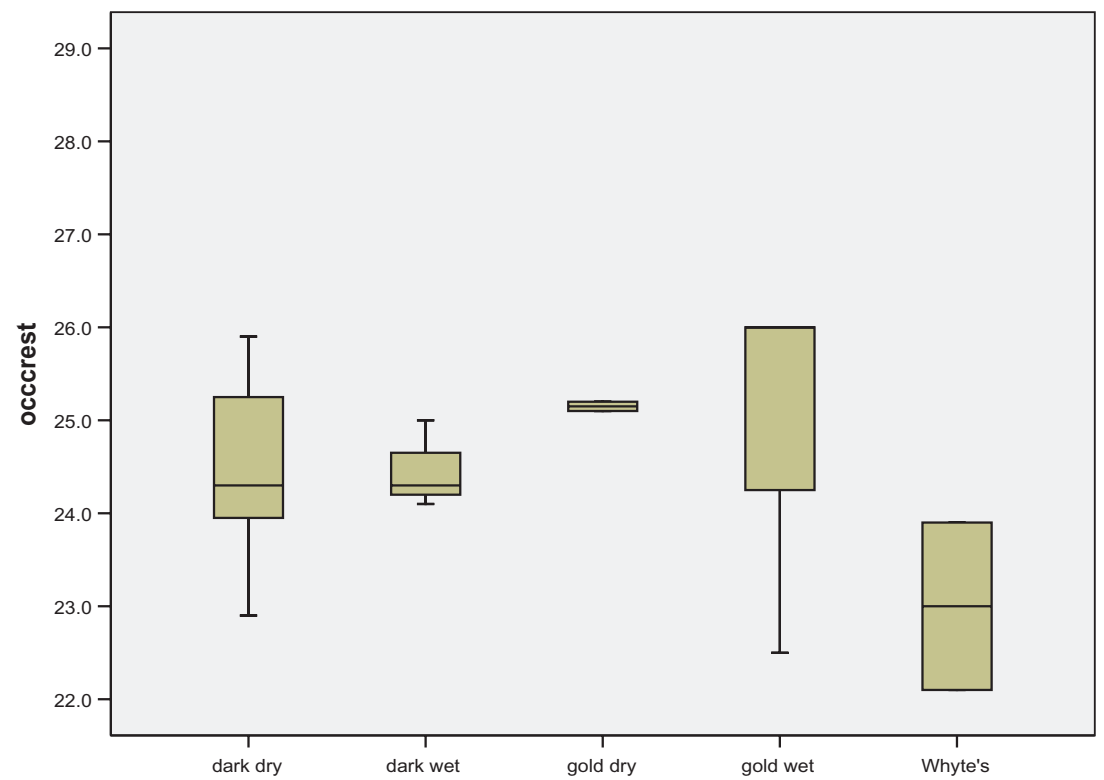

Figure 8. Occipital crest breadth (occcrest). Sample sizes as for Figure 6.

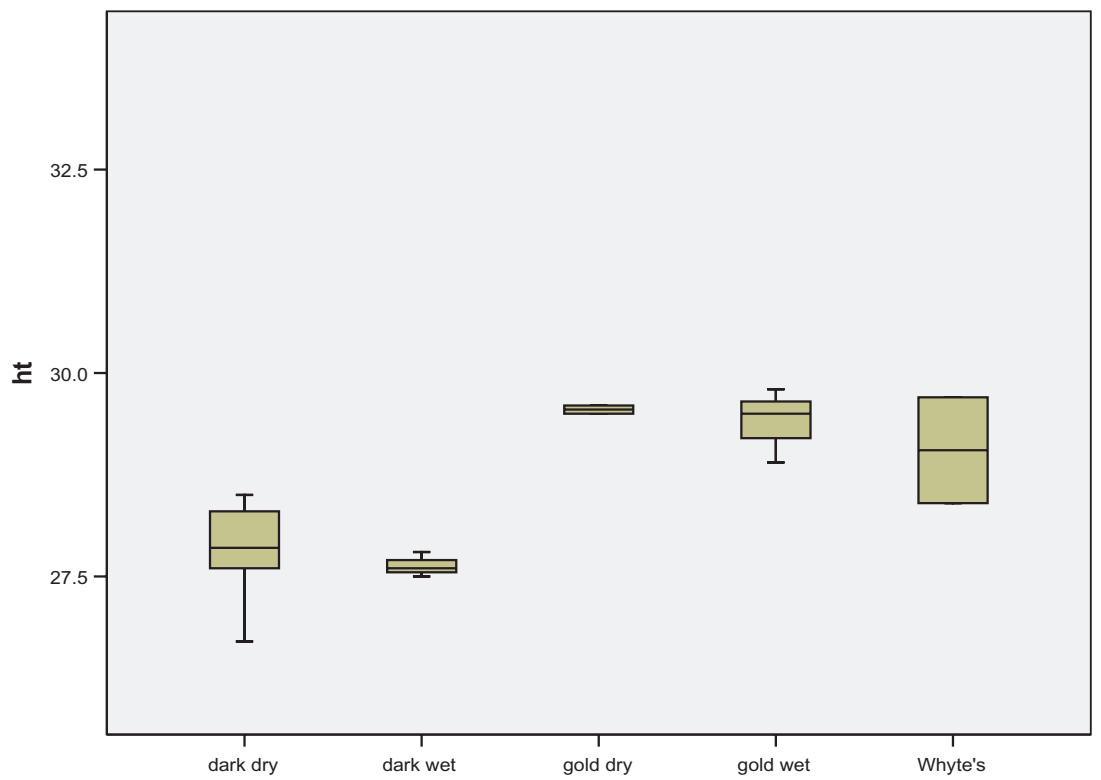

Figure 9. Skull height (ht). Sample sizes as for Figure 6, except that dark dry $=6$.

'Barbary'). It was not until 50 years later that Pocock (1933: 859-860) restored the name Paradoxurus zeylonensis to the golden palm civet, writing:

I can find no good reasons for dissenting from Kelaart's identification of this species. Pallas described his specimen as grey overspread with brown, paler below, blackish on the hinder part of the back and tail, the vibrissae being white. This description does not suit the few examples in the British Museum at the time Blanford wrote his revision of the Palm Civets in November 1885 and summarized in his volume in
1888; but specimens subsequently procured through the Survey [the Bombay Natural History Society's Mammal Survey of British India] show that the colour is much more variable than Blanford's descriptions suggest, varying, as enumerated below, from grey tinge with brown to a deep rich brown, with sometimes a dark blackish tinge on the back and upper side of the tail.

(Pocock 1933)

As a matter of fact, none of the specimens described by Pocock and examined by CPG show the colours 


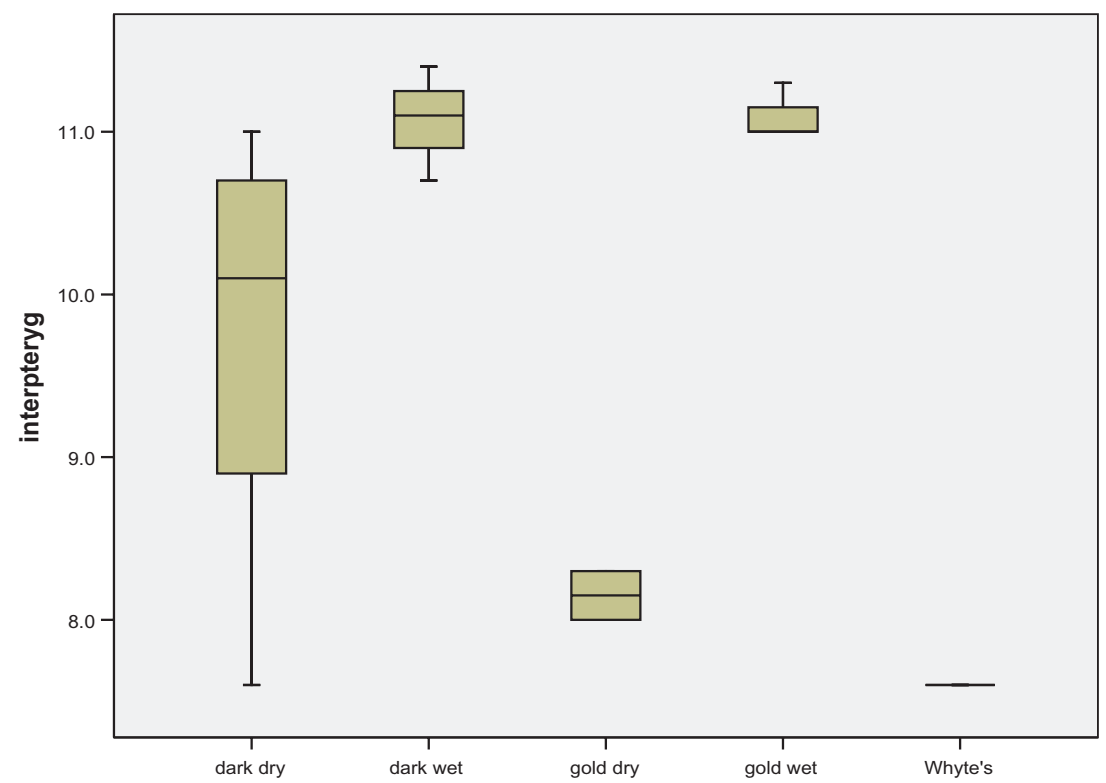

Figure 10. Interpterygoid width (interpteryg). Sample sizes as for Figure 6, except that Whyte's $=1$.

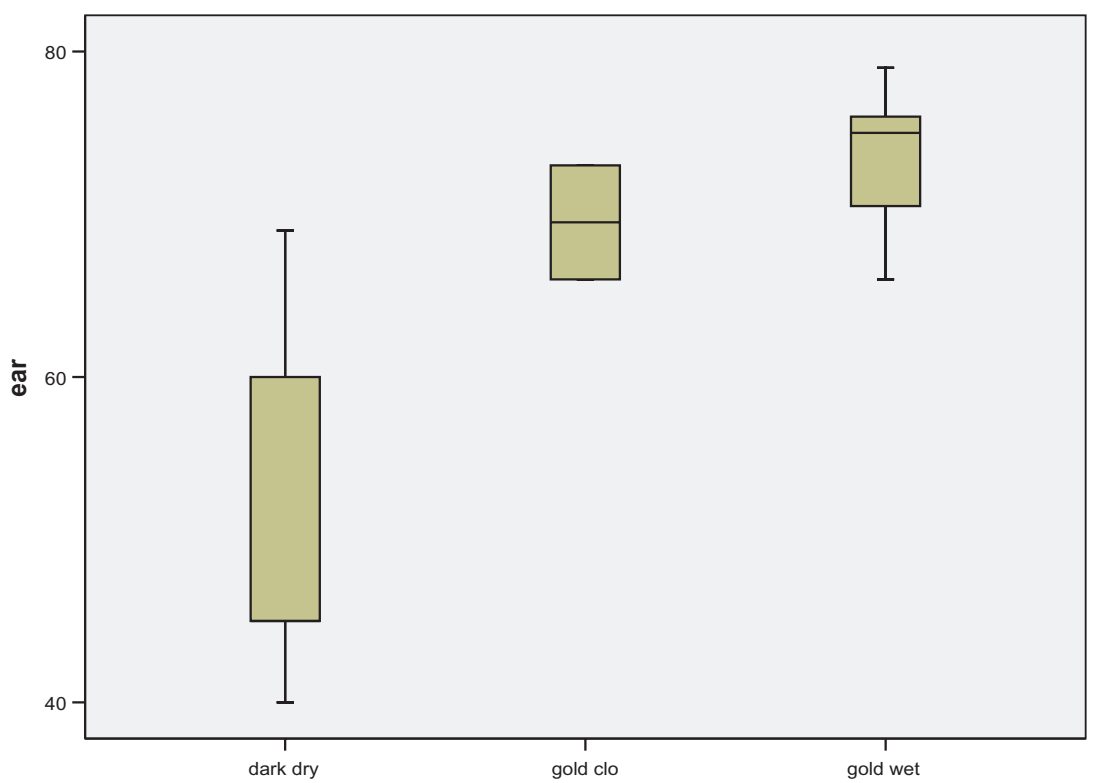

Figure 11. Ear length. Sample sizes are as follows: dark dry $=3$; gold cloud $=2$; gold wet $=7$.

described by von Schreber, in particular not the blackish hind parts. Although it is true that the whiskers are commonly black in $P$. hermaphroditus, they may also be light coloured, and the way that they curve backwards toward the ears is very reminiscent of von Schreber's description. We think it is most likely that the specimen was a common palm civet, of the morph, common in South Asia, lacking light facial spots. We do not know if 'the Nature Cabinet of His Highness the Crown Prince' still exists (preliminary enquiries by CPG have been unsuccessful), but until such time as it, and the specimen in question, may be rediscovered, we propose to set aside Pallas's name as being uncertain (and more likely to be a common rather than a 'golden' palm civet).

The first name that is certainly applicable to a golden palm civet is Paradoxurus aureus F. Cuvier, 1822. This was described from a young specimen preserved entire in the anatomy collection of the Paris Natural History Museum; after describing aspects of the external anatomy, Frédéric Cuvier wrote: 


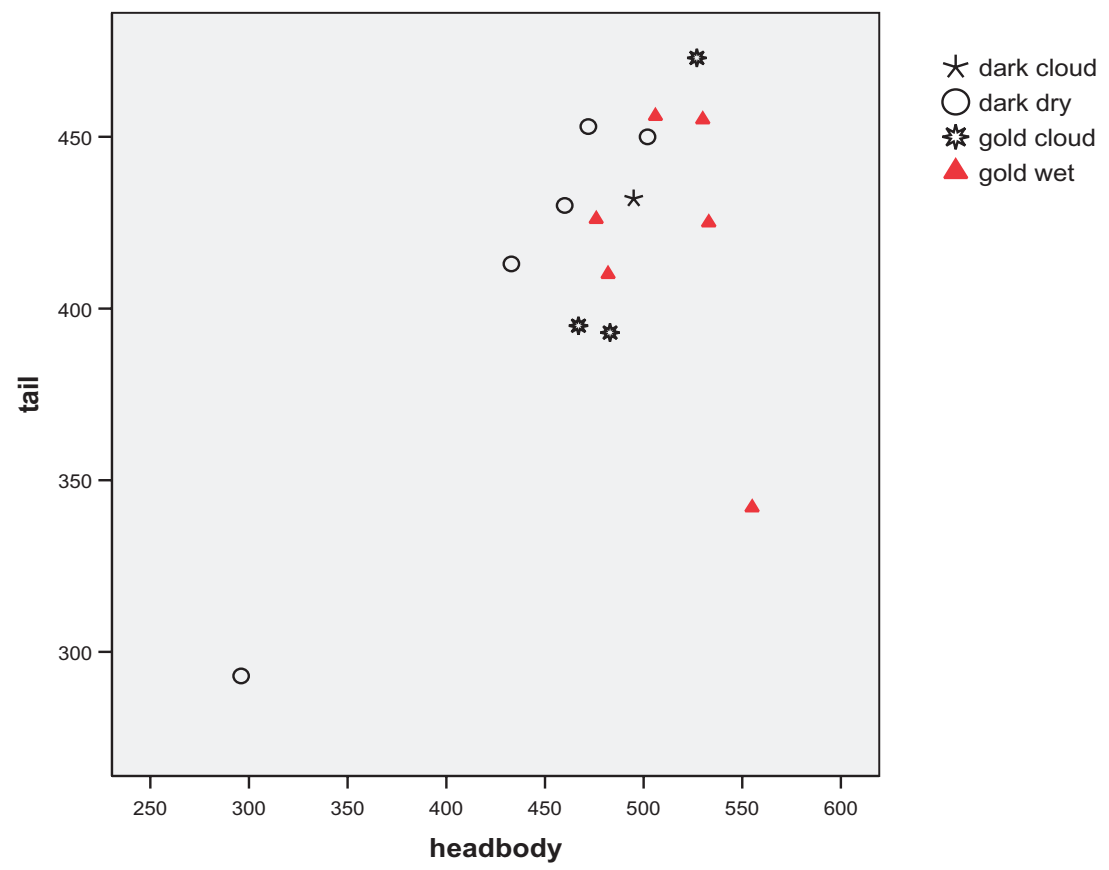

Figure 12. Tail length plotted against head + body length.

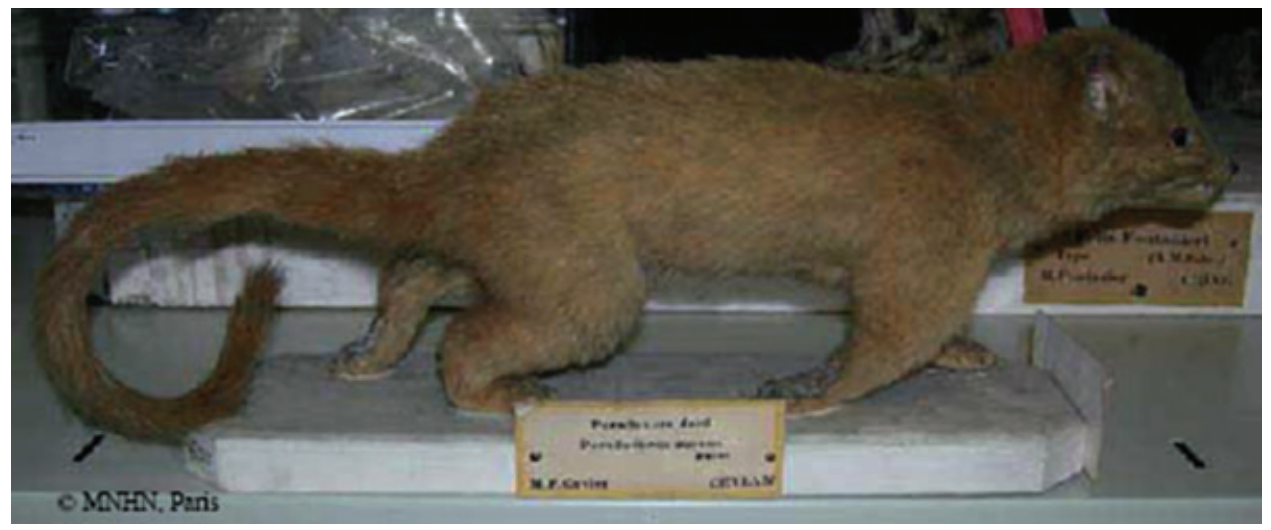

Figure 13. Type of Paradoxurus aureus F. Cuvier, 1822. Photo by C. Callou.

I have not been able to find out either from what country it originated, nor from where we obtained the individual . . . It is distinguished specifically . . . by its colour of a beautiful golden form uniformly spread over its entire body. Its pelage is not composed of very long hairs...

(F. Cuvier, 1822: 48)

The specimen, now prepared as a mounted skin, is still in the collection of the museum (Fig. 13, photo courtesy of Dr Cécile Callou). With due appreciation of the fact that it evidently spent some time preserved in spirits, and that it is doubtless somewhat faded, and is not fully mature, it is still possible to see that it is one of the golden species; it lacks the thin dark dorsal streaks of the dry-zone species, and can therefore be identified as the 'gold wet' species. Unexpect- edly, the locality 'Ceylan' appears on the label; whether this was, unknown to the describer, already known to be the place of origin, or whether it has been subsequently added, is unclear.

The only other name given to a Sri Lankan endemic palm civet is $P$. montanus. Kelaart (1852: 40) described a dark form, based on a specimen from Newara Eliya, under the heading 'VAR. - fuscus. (Paradoxurus montanus, $n, b$. )'. The style of this heading is enigmatic, as he first states that it is a variety, and then names it as a species, followed by ' $n$ ' (=nobis, i.e. 'attributed to us'; it is not clear what $b$ is intended to indicate). Although at first glance it might seem that Kelaart was giving it two alternative names, probably 'fuscus' (= dark) is intended simply to 
be descriptive, and certainly putting the name montanus in combination with the generic name makes it clearly available under the rules of nomenclature. The description claims that it is smaller than the 'ordinary variety', although the type (and only) specimen, which is in the Natural History Museum, London, is in fact subadult; the colour is 'rich dark brown' with no trace of markings; the tail is 'paler, with a ridge golden-yellow subterminal ring, which in the dried specimen has become partly albescent'.

\section{CONCLUSIONS}

At present, three species of endemic palm civet can be distinguished in Sri Lanka.

\section{Paradoxurus aureus F. Cuvier, 1822}

GOLDEN WET-ZONE PALM CIVET

Type: mounted skin, no number, in Muséum National d'Histoire Naturelle, Paris. The locality on the label is 'Ceylan' (Sri Lanka).

Diagnosis: Red-gold to golden brown, with no special markings. Underside a paler gold than upper side, usually sharply set off zone. Skull large, very broad across zygomatic arches, with a wide muzzle, a rather high, rounded braincase, and a wide square occipital crest, with parallel sides. Coronoid process of mandible curved strongly backwards.

Distribution: Wet and intermediate zones, submontane zone, and probably cloud forest in the Central Highlands, Namunukula, and the Knuckles Range (Dumbara). There is no evidence so far to separate cloud-forest specimens from those from the wet zone.

CR has live-trapped a single individual (a male) of this species, at Kalupahana, in the Knuckles Range.

\section{PARADOXURUS MONTANUS KELAART, 1852}

\section{SRI LANKAN BROWN PALM CIVET}

Type: BM 52.5.9.17, subadult male skin and skull, Newara Eliya, cloud-forest zone of Central Highlands, Sri Lanka.

Diagnosis: Dark, slightly greyish-toned wood-brown, with a yellowish-white tail tip. Underside a paler version of upper side. Skull smaller, narrow with a narrow, pointed muzzle, a lower, flatter braincase, and occipital crest narrows backwards. Coronoid process not strongly curved backwards.

Distribution: Dry zone of Sri Lanka, on present evidence extending to high altitudes in the Knuckles Range, and cloud forest in the Central Highlands.
Skulls from the wet zone are somewhat narrower, but with a wider interpterygoid fossa, and may be different; further material - especially of adult specimens - from the cloud forest may show that these populations are also different from those from the dry zone, in which case the cloud-forest animals would retain the name montanus, and lower-altitude taxa would require one or more new names.

CR has live-trapped 12 individuals of this species, as follows.

Knuckles Range: Memure, (1/1), Walpolamulla (1/0), Elukumbura (1/1).

Monaragala: Thabanna (4/1).

Bibila: Lunugala (0/1).

Ratnapura: Sirapagama (0/1).

\section{PARADOXURUS STENOCEPHALUS SP. NOV.}

\section{GOLDEN DRY-ZONE PALM CIVET}

Type: BM 50.1494, adult female skin and skull, Panama - sea coast, E.P., Sri Lanka.

Paratype: BM 33.7.24.1, adult male skin and (damaged) skull, Koslanda, Lipton's Tea Estate.

Diagnosis: Golden-brown, somewhat dull in tone, with three thin but clear dark brown stripes down the back from withers to near tail base. Underside paler, more gold than upper side, forming a sharply distinct pale zone. Skull like $P$. aureus F., large in size with wide muzzle, high braincase, square occipital crest with parallel sides, and coronoid process curved strongly backwards, but much narrower across zygomatic arches, and with narrow interpterygoid fossa.

Distribution: The species is so far known from only two specimens, the type and paratype, but as noted above, an animal (a male) trapped at Walpolamulla (625 m a.s.l.) in the Knuckles Range is identical. The consistency of the differences, in both external and craniomandibular features, is striking, and there seems no doubt that it is distinct.

Etymology: Narrow-headed $($ Greek stenos $=$ narrow, kephalos $=$ head).

\section{PARADOXURUS SP. NOV.?}

BM 77.11.1.3 and 77.11.1.4: these two specimens, presented by Whyte, and ticketed 'Ceylon, confined to the Hills', are different from any other specimens, as described above. We have suggested (above) that the locality may be in the Dickoya region at the eastern end of the Bogawantalawa valley, but until further 
evidence becomes available, it is impossible to contemplate describing a further species.

\section{SUMMARY}

The endemic palm civets (Paradoxurus) of Sri Lanka form not one single species but at least three: one of these is here described as new. They are distinguished by external features and by their skulls. Two of the species are golden in colour: one is known from two specimens from the dry zone, and the other is found in the wet zone, apparently extending into the cloud forest. By contrast, there is so far no evidence for any variation according to climatic zones in the dark-coloured species, and for the moment we class them in one single species. Two further specimens are quite different from any other, but owing to the uncertainty surrounding their provenance they cannot be described taxonomically.

The name $P$. zeylonensis, usually used for an endemic Sri Lankan palm civet, may well apply instead to the common palm civet, $P$. hermaphroditus. The earliest name definitely applicable to one of the presently described species is $P$. aureus F. Cuvier, 1822.

\section{ACKNOWLEDGEMENTS}

CPG is grateful to Paula Jenkins and Daphne Hills for access to specimens in the Natural History Museum, London, and CPG and KMA are grateful to Gamini Kumara Vithana for access to specimens in the National Museum of Sri Lanka, Colombo. CR gratefully acknowledges the kind support of Dr Devaka Weerakoon (University of Colombo) and Jayantha Jayawardena (Managing Trustee of the Biodiversity and Elephant Conservation Fund), and thanks the Director General of the Wildlife Department, Conservator of the Forest Department, and the National Zoological Garden for their assistance.

\section{REFERENCES}

Blanford WT. 1885a. Exhibition of the skull of a Paradoxurus. Proceedings of the Zoological Society 1885: 612-613.

Blanford WT. 1885b. A monograph of the genus Paradoxurus, F. Cuv. Proceedings of the Zoological Society 1885: 780-808.

Cuvier F. 1822. Du genre PARADOXURE et de deux espèces nouvelles qui s'y rapportent. Mémoires du Muséum d'Histoire Naturelle Paris 9: 41-48.

Groves C. 2001. Primate taxonomy. Washington: Smithsonian Institution Press.

Kelaart EF. 1852. Prodromus Faunae Zeylanicae. Colombo: WHT Publications (Private) Limited (Facsimile Edition, 1998).

Phillips WWA. 1984. Manual of the mammals of Sri Lanka, 2nd, revised edition, 3. Colombo: Wildlife and Nature Protection Society of Sri Lanka.

Pocock RI. 1933. The palm civets or 'toddy cats' of the genera Paradoxurus and Paguma inhabiting British India, Part I. Journal of the Bombay Natural History Society 36: 855-877.

von Schreber JCD. 1778. Die Säugethiere in Abbildungen nach der Natur mit Beschreibungen, 3. Erlangen: T.D. Weigel. 